\title{
Role of Dorsal Medial Prefrontal Cortex Dopamine DI-Family Receptors in Relapse to High-Fat Food Seeking Induced by the Anxiogenic Drug Yohimbine
}

\author{
Sunila G Nair', Brittany M Navarre', Carlo Cifani', Charles L Pickens', Jennifer M Bossert' and \\ Yavin Shaham*,1
}

'Behavioral Neuroscience Branch, NIDA/IRP/NIHIDHHS, Baltimore, MD, USA

\begin{abstract}
In humans, relapse to maladaptive eating habits during dieting is often provoked by stress. In rats, the anxiogenic drug yohimbine, which causes stress-like responses in both humans and nonhumans, reinstates food seeking in a relapse model. In this study, we examined the role of medial prefrontal cortex (mPFC) dopamine D I-family receptors, previously implicated in stress-induced reinstatement of drug seeking, in yohimbine-induced reinstatement of food seeking. We trained food-restricted rats to lever press for $35 \%$ high-fat pellets every other day (9-15 sessions, $3 \mathrm{~h}$ each); pellet delivery was accompanied by a discrete tone-light cue. We then extinguished operant responding for 10-16 days by removing the pellets. Subsequently, we examined the effect of yohimbine $(2 \mathrm{mg} / \mathrm{kg}$, i.p.) on reinstatement of food seeking and Fos (a neuronal activity marker) induction in mPFC. We then examined the effect of systemic injections of the D I-family receptor antagonist SCH23390 (10 $\mu \mathrm{g} / \mathrm{kg}$, s.c.) on yohimbine-induced reinstatement and Fos induction, and that of mPFC $\mathrm{SCH} 23390$ ( 0.5 and $1.0 \mu \mathrm{g} / \mathrm{side}$ ) injections on this reinstatement. Yohimbine-induced reinstatement was associated with strong Fos induction in the dorsal mPFC and with weaker Fos induction in the ventral mPFC. Systemic SCH23390 injections blocked both yohimbine-induced reinstatement and mPFC Fos induction. Dorsal, but not ventral, mPFC injections of SCH23390 decreased yohimbineinduced reinstatement of food seeking. In addition, dorsal mPFC SCH23390 injections decreased pellet-priming-induced reinstatement, but had no effect on ongoing high-fat pellet self-administration or discrete-cue-induced reinstatement. Results indicate a critical role of dorsal mPFC dopamine DI-family receptors in stress-induced relapse to palatable food seeking, as well as relapse induced by acute reexposure to food taste, texture, and smell.

Neuropsychopharmacology (20II) 36, 497-5I0; doi:10.1038/npp.20 I0.181; published online 20 October 2010
\end{abstract}

Keywords: diet; medial prefrontal cortex; reinstatement; relapse; stress; yohimbine

\section{INTRODUCTION}

Although many people attempt to control their excessive food intake, they typically relapse to old, unhealthy eating habits within a few months (Kramer et al, 1989; Peterson and Mitchell, 1999; Skender et al, 1996). This relapse is often induced by stress, anxiety, or negative mood states (Byrne et al, 2003; Grilo et al, 1989; Herman and Polivy, 1975; Polivy and Herman, 1999; Torres and Nowson, 2007). Despite evidence in humans of stress-induced relapse to unhealthy eating habits during dieting, until recently the mechanisms of this relapse have not been studied in animal

*Correspondence: Dr Y Shaham, Behavioral Neuroscience Branch, IRP/NIDA/NIH, 25I Bayview Boulevard, Suite 200, Baltimore, MD 21224, USA, Tel: + I 443740 2723, Fax: + I 4437402827 ,

E-mail: Yshaham@intra.nida.nih.gov

Received 20 June 2010; revised 21 August 2010; accepted 7 September 2010 models (Nair et al, 2009a). To address this issue, we adapted a rat reinstatement model, commonly used to study relapse to abused drugs (Shaham et al, 2003), to investigate mechanisms of stress-induced relapse to palatable food seeking during dieting (Ghitza et al, 2006). In these studies, we use the pharmacological stressor yohimbine to reinstate food seeking (Nair et al, 2009a).

We chose yohimbine (a prototypical $\alpha-2$ adrenoceptor antagonist) as the stress manipulation, because this pharmacological stressor has been used in many studies to induce stress- and anxiety-like states in both humans (Bremner et al, 1996b; Holmberg and Gershon, 1961) and nonhumans (Bremner et al, 1996a; Lang and Gershon, 1963). In addition, yohimbine reliably reinstates food seeking in rats (Ghitza et al, 2006; Nair et al, 2009b; Richards et al, 2008) and drug seeking in rats (Cippitelli et al, 2010; Feltenstein and See, 2006; Kupferschmidt et al, 2009; Shepard et al, 2004) and monkeys (Lee et al, 2004). 
The brain mechanisms of yohimbine-induced reinstatement of food and drug seeking are unknown, and results from studies on the role of central noradrenergic systems in this reinstatement are mixed. The $\alpha-2$ adrenoceptor agonist clonidine attenuates yohimbine-induced reinstatement of alcohol seeking in rats (Le et al, 2009) and cocaine seeking in monkeys (Lee et al, 2004). In contrast, clonidine exerts no effect on yohimbine-induced reinstatement of cocaine or food seeking in rats (Brown et al, 2009; Nair et al, 2009a), and yohimbine-induced reinstatement of cocaine conditioned place preference (CPP) in mice (Mantsch et al, 2010). In addition, in rats, 6-hydroxydopamine lesions of the ventral or dorsal noradrenergic bundles have no effect on yohimbine-induced reinstatement of alcohol seeking (Le et al, 2009). Furthermore, the effect of yohimbine on reinstatement of food or alcohol seeking is not mimicked by RS79948, a selective $\alpha-2$ adrenoceptor antagonist (Le et al, 2009; Nair et al, 2009a). In contrast, in monkeys, the effect of yohimbine on reinstatement is mimicked by RS79948 (Lee et al, 2004), and in mice, this effect of yohimbine is mimicked by another selective $\alpha-2$ adrenoceptor antagonist, BRL44408 (Mantsch et al, 2010). Mantsch et al (2010) also reported that yohimbine-induced cocaine CPP in mice is attenuated by the $\beta$-adrenoceptor antagonist, propranolol.

In this study, we studied the role of medial prefrontal cortex (mPFC) dopamine D1-family receptor in yohimbineinduced reinstatement of food seeking, because dorsal mPFC injections of the D1-family receptor antagonist SCH23390 or the mixed D1/D2 receptor antagonist fluphenazine decrease footshock-stress-induced reinstatement of cocaine seeking (Capriles et al, 2003; McFarland et al, 2004) and immobilization stress-induced reinstatement of cocaine CPP (Sanchez et al, 2003). In addition, stressors preferentially activate mesocortical dopaminergic projections from the ventral tegmental area to the mPFC (Deutch and Roth, 1990; Thierry et al, 1976). Finally, yohimbine increases mPFC extracellular dopamine levels (Tanda et al, 1996) and expression of Fos (a neuronal activity marker) (Bing et al, 1991, 1992; Funk et al, 2006; Singewald et al, 2003).

\section{MATERIALS AND METHODS}

\section{Subjects and Apparatus}

Male Long-Evans rats (total $n=114$, Charles River, Raleigh, NC; $300-385 \mathrm{~g}$ ) were maintained on a reverse 12-h:12-h light-dark cycle (lights off at 0900 or 0930 hours). In all, 16 rats were excluded from the study because of poor health, misplaced cannulae, intracranial injection procedure problems, or failure to meet the extinction criterion. All rats were weighed daily and food intake was restricted to $16 \mathrm{~g} /$ day of Purina rat chow (about $60-65 \%$ of their daily food intake) during the training phase and to $18-22 \mathrm{~g} /$ day (to maintain stable body weight) during the extinction and reinstatement test phases. All procedures followed the guidelines outlined in the 'Principles of Laboratory Animal Care' (NIH publication no. 85-23). Experiments were conducted in standard self-administration chambers (Med Associates, Georgia, VT). Each chamber had two levers $9 \mathrm{~cm}$ above the floor, but only one lever ('active,' retractable lever) activated the pellet dispenser, which delivered $45-\mathrm{mg}$ food pellets containing $35 \%$ fat and
45.2\% carbohydrate (catalog no. F05989, Bioserv, Frenchtown, NJ). Efforts were made to minimize the number of animals used and their suffering.

\section{Drugs}

SCH23390 hydrochloride and MK212 hydrochloride were purchased from Tocris (Ellisville, MO), yohimbine hydrochloride was purchased from Sigma (St Louis, MO), and M100907 was provided by Dr Kenner Rice (NIDA). SCH23390 (injection volume of $1 \mathrm{ml} / \mathrm{kg}$ or $0.5 \mu \mathrm{l} /$ side for systemic or intracranial injections, respectively) and MK212 $(0.5 \mu \mathrm{l} /$ side $)$ were dissolved in sterile saline; M100907 $(0.5 \mu \mathrm{l} /$ side $)$ was dissolved in a minimal volume of $0.01 \mathrm{~N}$ $\mathrm{HCl}$ and sterile saline and the $\mathrm{pH}$ of the solution was adjusted to 6-7 with $0.1 \mathrm{~N} \mathrm{NaOH}$. Yohimbine $(0.5 \mathrm{ml} / \mathrm{kg})$ was dissolved in sterile water. Doses of yohimbine, SCH23390, MK212, and M100907 are based on our studies (Bossert et al, 2007, 2009; Ghitza et al, 2007; Nair et al, 2008, $2009 \mathrm{~b}$ ) and on studies of other investigators (Alleweireldt et al, 2006; Anderson et al, 2003; Bachtell et al, 2005; Bossert et al, 2009; Chaudhri et al, 2009; Filip and Cunningham, 2003; McMahon et al, 2001; Pentkowski et al, 2010; Ramos et al, 2005; See, 2009).

\section{Intracranial Surgery}

Rats were anesthetized with a mixture of sodium pentobarbital and chloral hydrate (60 and $25 \mathrm{mg} / \mathrm{kg}$, i.p.). For intracranial injection studies, rats were implanted with bilateral guide cannulae ( $23 \mathrm{G}$, Plastics One, Roanoke, VA) $1 \mathrm{~mm}$ above the dorsal mPFC (cingulate area 1 and dorsal part of the prelimbic cortex) (AP: $+2.8 \mathrm{~mm}$, ML: $+1.2 \mathrm{~mm}$, and DV: $-2.4 \mathrm{~mm}, 10^{\circ}$ angle) or the ventral $\mathrm{mPFC}$ (ventral part of the prelimbic cortex and infralimbic cortex) (AP: + $2.8 \mathrm{~mm}$, ML: $+1.5 \mathrm{~mm}$, and DV: $-4.2 \mathrm{~mm}, 10^{\circ}$ angle) (Paxinos and Watson, 2005). These coordinates are based on a previous study from our laboratory (Koya et al, 2009). The analgesic buprenorphine $(0.1 \mathrm{mg} / \mathrm{kg}$, s.c.) was administered after surgery and rats were allowed to recover for at least 7 days.

\section{Intracranial Injections}

Intracranial injections of SCH23390, MK212, M100907, or their vehicles were prepared with Harvard infusion pumps, using 10- $\mu$ l Hamilton syringes connected to $30-\mathrm{G}$ injectors (Plastics One) by polyethylene-50 tubing. Injections lasted $1 \mathrm{~min}$ and injectors were left in place for an additional minute before being replaced with cannula blockers. After the last reinstatement test, rats in experiments 2-4 were deeply anesthetized, decapitated, and their brains were removed and stored in $10 \%$ formalin. The brains were sliced into coronal sections (of 50- $\mu \mathrm{m}$ thickness) and stained with cresyl violet. The sections were then examined for cannulae placement under a microscope.

\section{Fos Immunohistochemistry}

All experiments described below were carried out at room temperature unless specified. Ninety minutes after the start of the test sessions ( $\sim 120 \mathrm{~min}$ after yohimbine injections), 
rats were deeply anesthetized with isoflurane $(\sim 80 \mathrm{~s})$ and perfused transcardially with $100 \mathrm{ml}$ of $0.1 \mathrm{M}$ phosphatebuffered saline (PBS), followed by $400 \mathrm{ml}$ of $4 \%$ paraformaldehyde in $0.1 \mathrm{M}$ sodium phosphate ( $\mathrm{pH} 7.4$ ). The brains were removed, post fixed in $4 \%$ paraformaldehyde for $2 \mathrm{~h}$, and transferred to $30 \%$ sucrose in $0.1 \mathrm{M}$ sodium phosphate ( $\mathrm{pH} 7.4$ ) for $48 \mathrm{~h}$ at $4{ }^{\circ} \mathrm{C}$. The brains were subsequently frozen in powdered dry ice and stored at $-80^{\circ} \mathrm{C}$ until sectioning. Coronal sections of $40-\mu \mathrm{m}$ thickness, approximately +2.5 to $3.5 \mathrm{~mm}$ from the bregma (Paxinos and Watson, 2005), containing the dorsal and ventral mPFCs were cut on a cryostat (Leica Microsystems, Bannockburn, IL), collected in cryoprotectant (20\% glycerol and $2 \%$ dimethylsulfoxide in $0.1 \mathrm{M}$ sodium phosphate, $\mathrm{pH} 7.4$ ), and stored at $-80{ }^{\circ} \mathrm{C}$ until further processing.

Free-floating sections were washed (3 times for $10 \mathrm{~min}$ each) in PBS, incubated for $1 \mathrm{~h}$ in $3 \%$ normal goat serum (NGS) in PBS with $0.2 \%$ Triton X-100 (PBS-Tx), and incubated overnight at $4{ }^{\circ} \mathrm{C}$ with the anti-c-Fos primary antibody (c-Fos sc-52, Lot F2209, Santa Cruz Biotechnology) diluted 1:4000 in 1\% NGS in PBS-Tx. The sc-52 antibody was raised against amino acids 3-16 of human c-Fos: SGFNADYEASSSRC. Sections were then washed in PBS and incubated for $2 \mathrm{~h}$ with the biotinylated anti-rabbit IgG secondary antibody (BA-1000, Vector Laboratories) diluted 1:600 in 1\% NGS in PBS-Tx. Sections were washed in PBS and incubated in avidin-biotin-peroxidase complex (ABC Elite kit, PK-6100, Vector Laboratories) in PBS containing $0.5 \%$ Triton X-100 for $1 \mathrm{~h}$, and washed in PBS. Sections were developed in $3,3^{\prime}$-diaminobenzidine for $\sim 4$ min, washed in PBS, mounted onto chrom-alum/gelatincoated slides, and air dried. The slides were dehydrated through a graded series of alcohol $(30,60,90,95,100,100 \%$ ethanol), cleared with Citrasolv (Fisher Scientific, Pittsburgh, PA), and coverslipped with Permount (Sigma).

Bright field images of the dorsal and ventral mPFCs were digitally captured using a CCD Camera (Coolsnap Photometrics, Roper Scientific, Trenton, NJ) attached to a Zeiss Axioskop 2 microscope with a $\times 5$ objective. Labeled Fos-immunoreactive nuclei from 1-2 sections from the left and right hemispheres of each rat under different experimental conditions were automatically counted using IPLab software (version 3.9.4 r5; Scanalytics, Fairfax, VA) for Macintosh. Image capture and quantification of Fospositive nuclei were conducted in a blind manner by CC and independently verified in selected sections by JMB (inter-rater reliability $r=0.81, p<0.05$ ).

\section{Double Labeling with Fos and NeuN Immunohistochemistry}

Double-labeling experiments for Fos and the neuronal marker NeuN were used to estimate the proportion of neurons expressing Fos. Sections from 6 rats from experiment 1 ( $n=3$ for vehicle and yohimbine conditions) were thawed and washed ( 3 times for $10 \mathrm{~min}$ each) in Trisbuffered saline (TBS; $0.025 \mathrm{M}$ Tris- $\mathrm{HCl}, 0.5 \mathrm{M} \mathrm{NaCl}, \mathrm{pH} 7.5$ ) and incubated for $20 \mathrm{~min}$ in TBS with $0.2 \%$ Triton X-100 (TBS-Tx). Sections were washed in TBS and incubated for $48 \mathrm{~h}$ with antibody to Fos (1:500 dilution, sc-52) and antibody to NeuN (1:2000 dilution of MAB377, Millipore) in TBS-Tx. Sections were washed in TBS and incubated for
$1 \mathrm{~h}$ with secondary antibodies Alexa 488-labeled donkey anti-rabbit antibody and Alexa 568-labeled goat anti-mouse antibody ( $1: 200$ dilution in TBS-Tx for both antibodies, Invitrogen). Finally, sections were washed in TBS, mounted on to chrom-alum/gelatin-coated slides, air dried, and coverslipped using the Vectashield fluorescent mounting medium (H-1400, Vector Laboratories). Fluorescent images of the dorsal and ventral mPFCs were captured using the same CCD camera and microscope using a $\times 20$ objective. The number of Fos-labeled, NeuN-labeled, and doublelabeled immunoreactive nuclei in these images were manually counted in a blind manner by CC.

\section{Behavioral Procedures}

We used a reinstatement procedure that included 3 phases: training for food self-administration (9-15 sessions), extinction of food-reinforced behavior (10-16 sessions), and tests for reinstatement under extinction conditions (2-4 sessions). During all phases, the sessions started $30 \mathrm{~min}$ after the beginning of the dark cycle (0930 or 1000 hours). Below, we first describe the training and extinction procedures for all experiments, and then provide specific details for the testing phase of each experiment. During testing, the experimental conditions were counterbalanced.

\section{Food Self-Administration Training}

All rats underwent 3-h daily sessions of 'autoshaping' for 2-3 days during which pellets were administered noncontingently every $5 \mathrm{~min}$ into a receptacle located near the active lever. Pellet delivery was accompanied by a compound 5 -s tone $(2900 \mathrm{~Hz})$-light $(7.5-\mathrm{W}$ white light located above the active lever) cue. Subsequently, rats were trained to self-administer the pellets on a fixed-ratio 1, 20-s timeout reinforcement schedule. Training sessions were conducted for 9-15 days, every other day, $3 \mathrm{~h} /$ day over 18-30 days. Rats were chronically housed in operant selfadministration chambers for the entire duration of training, with the exception of 19 rats (10 in experiment $2 a$ and 9 in experiment $2 \mathrm{~b}$ ). Due to scheduling issues, for 10 training days, these rats were housed in the animal facility and transferred to the self-administration chambers before the training sessions, and returned to the facility at the end of the 3-h sessions. From training day 11 onwards, these rats were housed in operant chambers.

At the start of each 3-h session, the red houselight was turned on and the active lever was extended. After each pellet delivery, the tone-light cue was turned on for $5 \mathrm{~s}$. During the training days, regular food (16g Purina rat chow) was given immediately after the daily session $(\sim 3.5 \mathrm{~h}$ into the dark cycle). During the days off, $16 \mathrm{~g}$ regular food was given at the start of the dark cycle. We chose this training schedule and these diet conditions because previous home-cage food-consumption studies have shown that rats placed on a restricted diet and given intermittent access to palatable food develop binge-like eating behavior (Avena et al, 2008; Boggiano et al, 2007; Colantuoni et al, 2002; Corwin and Buda-Levin, 2004; Figlewicz et al, 2007) and become hypersensitive to the effect of stress on palatable food intake (Cifani et al, 2009; Hagan et al, 2002, 2003). 


\section{Extinction of Food-Reinforced Responding}

After training, rats underwent $10-16$ daily 3 -h extinction sessions until active lever responding decreased to 30 presses $/ 3 \mathrm{~h}$ or less for 3 consecutive sessions (the extinction criterion). In experiments $1,3 \mathrm{a}$, and $3 \mathrm{~b}$, during the extinction phase, lever presses led to tone-light cue presentations, but not to pellet delivery. In experiment $3 \mathrm{c}$ (cue-induced reinstatement), lever presses during the extinction phase had no programmed consequences (ie, neither the tone-light cue nor pellets were made available). During the extinction and reinstatement phases, regular food (18-22 g) was given approximately at the same time as during training phases $(\sim 3.5 \mathrm{~h}$ after the onset of the dark cycle). In all experiments, the amount of food given during the extinction phase was higher than that given during the training phase to maintain rats on a stable body weight during this phase and the subsequent reinstatement phase.

\section{Experiment 1: Effect of Systemic SCH23390 Injections on Yohimbine-Induced Reinstatement and mPFC Fos Induction}

Experiment 1a: In this initial experiment, we studied the effect of yohimbine or vehicle injections ( $n=7$ per group) on reinstatement of lever responding and Fos induction in the dorsal and ventral mPFCs. Rats were injected with yohimbine $(2 \mathrm{mg} / \mathrm{kg}$, i.p.) or distilled water $25-30 \mathrm{~min}$ before the start of 90-min test sessions. The test session duration was shorter than that of the subsequent experiments $(3 \mathrm{~h})$, because of the time course of Fos protein expression, which is maximal $90-120 \mathrm{~min}$ after neuronal activation (Curran and Morgan, 1995). At the end of testing, rats were anesthetized, perfused, and their brains were removed and assayed for Fos-IR (see above).

Experiment $1 b$. Fos induction is dependent on activation of D1-family receptor signaling (Graybiel et al, 1990; Robertson et al, 1989; Young et al, 1991), and we previously found that systemic SCH23390 injections (5 and $10 \mu \mathrm{g} / \mathrm{kg}$, s.c.) decrease yohimbine-induced reinstatement of food seeking (Figure 2 in Nair et al, 2009a). Therefore, we assessed whether yohimbine-induced reinstatement and $\mathrm{mPFC}$ Fos induction are reversed by systemic SCH23390 injections. We used 4 groups of rats $(n=6-7$ per group) in a 2 (SCH23390 dose: $0,10 \mu \mathrm{g} / \mathrm{kg}$ ) $\times 2$ (yohimbine dose: $0,2 \mathrm{mg} /$ $\mathrm{kg}$ ) experimental design. Rats were injected with $\mathrm{SCH} 23390$ or saline immediately before yohimbine or distilled water injections, administered $25-30 \mathrm{~min}$ before the start of test sessions. At the end of testing, rats were anesthetized, perfused, and their brains were removed and assayed for Fos-IR.

\section{Experiment 2: Effect of Dorsal and Ventral mPFC Injections of SCH23390 on Yohimbine-Induced Reinstatement}

Experiment 2a: dorsal mPFC. In experiment 1, we found that systemic yohimbine injections preferentially increased Fos expression in the dorsal mPFC and that this effect was blocked by systemic SCH23390 injections. In this experiment, we tested whether local SCH23390 would mimic the systemic effect of the drug on yohimbine-induced reinstatement. We tested the effect of dorsal mPFC SCH23390 injections on yohimbine-induced reinstatement in four test sessions with two sessions run consecutively and one extinction day between sets of tests. We used two groups ( $n=8-12$ per group) in a mixed experimental design that included the between-subjects factor of SCH 23390 dose (0.5, $1.0 \mu \mathrm{g} / \mathrm{site})$, and the within-subjects factors of pretreatment condition (vehicle, SCH23390 (0.5 or $1.0 \mu \mathrm{g} / \mathrm{site})$ ), and yohimbine dose $(0,2 \mathrm{mg} / \mathrm{kg})$. Rats were injected intracranially with SCH 23390 or saline, followed immediately by i.p. injections of yohimbine or distilled water 25-30 min before the start of test sessions. The experimental conditions were counterbalanced. The rationale for using the mixed experimental design described above, which was also used in our previous work (Ghitza et al, 2007; Nair et al, 2008, 2009b), is to minimize the number of rats used while limiting the number of repeated yohimbine reinstatement tests. At the end of the experiment, rats were anesthetized, decapitated, and their brains were removed for verification of cannulae placements.

Experiment $2 b$ : ventral $m P F C$. In experiment $2 a$, we found that dorsal mPFC SCH23390 injections decreased yohimbine-induced reinstatement. In experiment $2 b$, we tested the anatomical selectivity of this effect by injecting SCH23390 into the ventral mPFC. Although both SCH23390 doses were effective in the dorsal mPFC (Figure 4), we used the higher dose $(1 \mu \mathrm{g})$ to assess anatomical specificity (experiment $2 \mathrm{~b}$ ) and behavioral specificity (experiment 3 ), because negative results from intracranial injections of a given receptor antagonist (or agonist) can be interpreted with more confidence than negative findings with half the drug dose. This is because of the fact that for a constant injection volume, the higher drug dose can achieve higher receptor occupancy and can diffuse further away from the injection site (Wise and Hoffman, 1992). We tested the effect of ventral mPFC SCH23390 injections on yohimbine-induced reinstatement in four test sessions with two sessions run consecutively and one extinction day between sets of tests. We used a within-subjects experimental design that included the factors of pretreatment condition (vehicle, SCH23390 $(1.0 \mu \mathrm{g} / \mathrm{site}))$ and yohimbine dose $(0,2 \mathrm{mg} / \mathrm{kg})$ $(n=9)$. Rats were injected intracranially with SCH23390 or saline, followed immediately by i.p. injections of yohimbine or distilled water 25-30 min before the start of test sessions. The experimental conditions were counterbalanced. At the end of the experiment, rats were anesthetized, decapitated, and their brains were removed for verification of cannulae placements.

\section{Experiment 3: Effect of Dorsal mPFC Injections of SCH23390 on Food Self-Administration, and Pellet-Priming- and Cue-Induced Reinstatement}

The purpose of experiment 3 was to determine the behavioral specificity of the effect of dorsal mPFC SCH23390 on yohimbine-induced reinstatement by assessing its effect on ongoing pellet self-administration, as well as reinstatement of food seeking induced by pellet priming and discrete cues. These stimuli reliably reinstate lever 
presses under our experimental conditions (Nair et al, 2008, 2009b).

Experiment 3a: pellet self-administration. We tested the effect of dorsal mPFC injections of SCH23390 $(1.0 \mu \mathrm{g} /$ side $)$ or saline $(0.5 \mu \mathrm{l} / \mathrm{side})$ on ongoing food self-administration. A single group of rats $(n=10)$ was used in a within-subjects design in which rats were tested, under counterbalanced conditions, on training days 11 and 14 . The mean pellet intake and active lever responding for the two training sessions before the test days were $249 \pm 25$ and $1085 \pm 258$ per $3 \mathrm{~h}$, respectively. Rats were injected intracranially with $\mathrm{SCH} 23390$ or saline $25-30 \mathrm{~min}$ before the start of test sessions.

Experiment 3b: pellet-priming-induced reinstatement. We tested the effect of dorsal mPFC injections of SCH23390 $(1.0 \mu \mathrm{g} /$ side $)$ or saline on pellet-priming-induced reinstatement of lever responding. It is well established that noncontingent exposure to a food pellet after extinction of operant responding reinstates food seeking (Baker et al, 1991; Horvitz and Ettenberg, 1988; Skinner, 1938). We used the same rats $(n=10)$ that were used in experiment $3 a$. After the second test session in experiment $3 \mathrm{a}$, these rats underwent 15 extinction sessions during which lever responding led to tone-light cue presentations, but not pellets. Rats were then tested under counterbalanced conditions for pellet-priming-induced reinstatement. The test sessions were separated by 3 days and rats underwent regular extinction sessions on the days between testing. During testing, saline or SCH23390 was injected into the dorsal mPFC 25-30 min before exposure to the pellet priming manipulation: noncontingent delivery of 3 pellets, every $20 \mathrm{~s}$, at the onset of the sessions. After the second test session, rats were anesthetized, decapitated, and their brains were removed for verification of cannulae placements. In experiment 2, we found that dorsal mPFC saline or SCH23390 injections had no effect on baseline extinction responding. Thus, to limit the number of intracranial injections, we did not assess this in experiment $3 \mathrm{~b}$ (and in experiments $3 \mathrm{c}, 4 \mathrm{a}$, and $4 \mathrm{~b}$ ).

Experiment 3c: cue-induced reinstatement. We tested the effect of dorsal mPFC injections of SCH23390 $(1.0 \mu \mathrm{g} /$ side $)$ or saline on cue-induced reinstatement of lever responding. For this purpose, we used a well-established cue-induced reinstatement procedure that has been used in studies involving food (De Vries et al, 2005; Floresco et al, 2008; McLaughlin and Floresco, 2007) and drug (Davis and Smith, 1976; Meil and See, 1996) rewards. In this procedure, rats are first trained to self-administer a drug or nondrug reward; each reward delivery is temporally paired with a discrete cue (eg, tone, light). Lever pressing is then extinguished in the absence of the reinforcer and the cue. During reinstatement testing, exposure to the cue, which is earned contingently during testing, serves as a conditioned reinforcer and reliably reinstates operant responding (See, 2005). A single group of rats $(n=10)$ was trained to lever press for food pellets for nine sessions as described above. Next, rats underwent 10 extinction sessions during which neither pellets nor tone-light cues were delivered after the lever press. Rats were then tested under counterbalanced conditions for cue-induced reinstatement. Rats were injected intracranially with $\mathrm{SCH} 23390$ or saline 25-30 min before the start of test sessions; during the sessions, lever responding led to contingent presentations of the cue under a fixed-ratio 1, 20-s timeout reinforcement schedule. The test sessions were separated by 4 days and rats underwent extinction sessions (without the discrete cue) on the days between testing. Rats that did not initiate lever responding within $10 \mathrm{~min}$ of the start of the session were given a single noncontingent exposure to the tonelight cue.

\section{Experiment 4: Effect of Dorsal mPFC Injections of the 5-HT2c Agonist MK212 and the 5-HT2a Antagonist M100907 on Yohimbine-Induced Reinstatement}

Experiment 4a: MK212. $\mathrm{SCH} 23390$ is also a 5-HT2c (formerly 5-HT1c) receptor agonist (Briggs et al, 1991; Millan et al, 2001), and Fletcher et al (2008) found that systemic injections of the 5-HT2c receptor agonist Ro600175 decrease yohimbine-induced reinstatement of cocaine seeking. Thus, we determined whether dorsal mPFC SCH23390 effects on yohimbine-induced reinstatement are mimicked by the 5-HT2c receptor agonist MK212 (Ramos et al, 2005). At the end of experiment 3c (cue-induced reinstatement), rats underwent seven extinction sessions in the presence of the tone-light cue and then tested for yohimbine-induced reinstatement in two counterbalanced sessions (separated by 4 days) after pretreatment with MK212 $(0.1 \mu \mathrm{g} / 0.5 \mu \mathrm{l}$ per side) or vehicle (sterile saline) into the dorsal mPFC. MK212 was injected just before yohimbine ( $2 \mathrm{mg} / \mathrm{kg}$, i.p.), which was injected $25-30 \mathrm{~min}$ before the test sessions. After the second test session, rats were anesthetized, decapitated, and their brains dissected for cannulae placement verification.

Experiment 4b: M100907. SCH23390 also binds to 5-HT2a receptors with high affinity (Neumeyer et al, 2003; Porter et al, 1999). Results from pharmacological studies indicate that $\mathrm{SCH} 23390$ is an antagonist at 5-HT2a receptors, because it blocks behavioral and physiological effects of 5-HT2a receptor stimulation (Monti et al, 1990; Schreiber et al, 1995). Thus, we determined whether the effects of dorsal mPFC SCH23390 on yohimbine-induced reinstatement are mimicked by the 5-HT2a receptor antagonist M100907 (McMahon et al, 2001). Rats $(n=9)$ were trained to self-administer high-fat food pellets as described above. Next, lever responding was extinguished in the presence of the tone-light cue for 10 days. Rats were then tested for yohimbine-induced reinstatement in two counterbalanced sessions (separated by 2 days) after pretreatment with M100907 $(0.3 \mu \mathrm{g} / 0.5 \mu \mathrm{l}$ per side) or vehicle (sterile saline) into the dorsal mPFC. M100907 was injected just before yohimbine $(2 \mathrm{mg} / \mathrm{kg}$, i.p.), which was injected $25-30 \mathrm{~min}$ before the test sessions. After the second test session, rats were anesthetized, decapitated, and their brains were removed for verification of cannulae placements.

\section{Statistical Analyses}

Data were analyzed using mixed ANOVAs in SPSS version 15.0 statistical software Proc GLM procedure. In experiment 1, 
the number of Fos-IR and NeuN nuclei for the dorsal and ventral mPFCs was determined by calculating the mean value of two hemispheres per rat. The factors used in statistical analyses are described in the 'Results' section. Significant overall effects $(p<0.05)$ in the different ANOVAs were followed by post hoc Fisher PLSD tests.

\section{RESULTS}

Rats (total $n=98$ ) were trained to self-administer food pellets for 9-15 days $(3 \mathrm{~h} /$ day) and demonstrated reliable pellet self-administration and, as in our previous studies (Ghitza et al, 2006; Nair et al, 2008, 2009b), a progressive escalation of timeout active lever presses across sessions (Figure 1; $p$-values $<0.01$ for a training session effect for both pellet intake and timeout responding). After selfadministration training, rats underwent $10-16,3$-h extinction sessions either in the presence (experiment $1,2,3 \mathrm{~b}, 4 \mathrm{a}$, and $4 \mathrm{~b}$, total $n=88$ ) or absence (experiment $3 \mathrm{c}, n=10$ ) of the discrete tone-light cue, during which lever pressing decreased over days under both extinction conditions (Figure 1; $p$-values $<0.01$ for an extinction session effect).
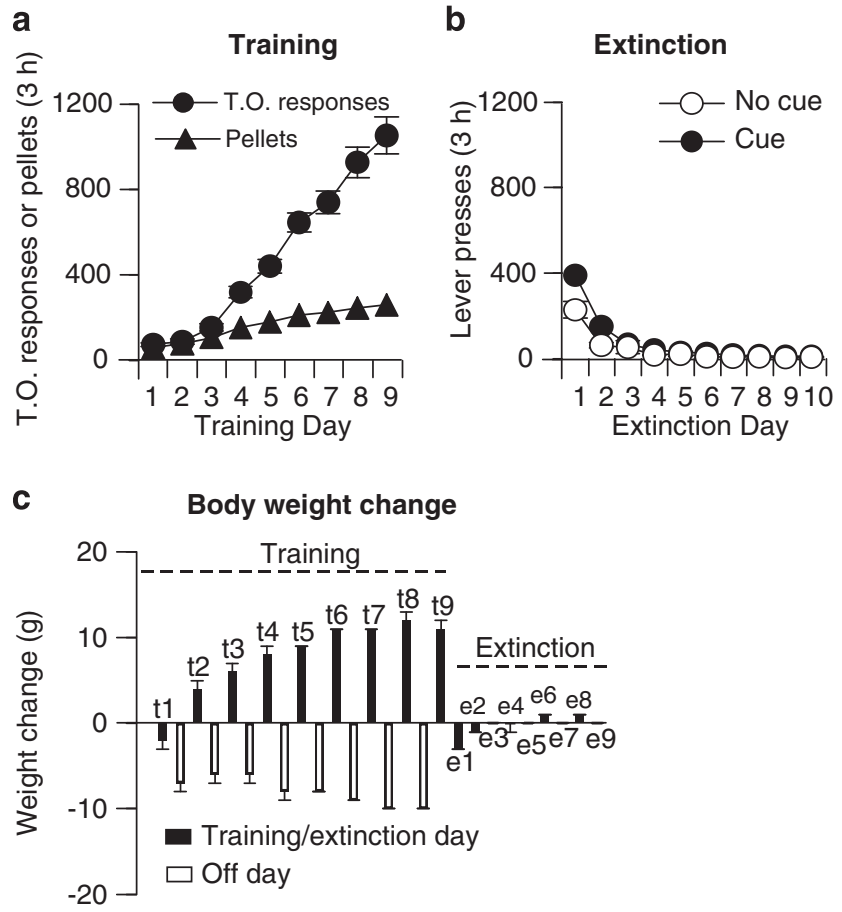

Figure I Food pellet self-administration training, extinction of foodreinforced lever responding, and body weight change. (a) Training (first 9 days): mean \pm SEM number of $35 \%$ fat pellets earned and timeout (T.O.) responses on the active lever (total lever presses minus pellets earned) during the training sessions, which occurred on alternate days (one 3-h session per day, every other day). Rats were trained on a fixed-ratio I (FR-I) 20-s timeout reinforcement schedule $(n=98)$. (b) Extinction (first 9 days): mean \pm SEM number of responses on the previously active lever in the presence $(n=88)$ or absence $(n=10$, experiment $3 c)$ of a discrete tone-light cue. (c) Body weight fluctuations during training and extinction phases $(n=98)$. During the training phase, rats were maintained on $16 \mathrm{~g} /$ day of regular chow food and were given 3-h access to food pellets every other day. During the extinction (and reinstatement) phases, food pellets were not available in the self-administration chambers, and rats were maintained on 18-22 g/day of regular chow to maintain stable body weight.
Experiment 1: Effect of systemic SCH23390 Injections on Yohimbine-Induced Reinstatement and mPFC Fos Induction

Experiment 1a. Yohimbine reinstated active lever responding after extinction; this effect was associated with strong and moderate Fos induction in the dorsal and ventral mPFCs, respectively (Figure 2). Behavioral data were analyzed using the between-subjects factor of yohimbine dose $(0,2 \mathrm{mg} / \mathrm{kg})$ and the within-subjects factor of lever (active, inactive). ANOVA revealed significant effects of yohimbine dose $\left(\mathrm{F}_{1,12}=47.6, p<0.01\right)$, lever $\left(\mathrm{F}_{1,12}=66.1\right.$, $p<0.01)$, and yohimbine dose $\times$ lever $\left(\mathrm{F}_{1,12}=46.3\right.$, $p<0.01)$. Yohimbine had no effect on inactive lever presses, a potential measure of nondirected activity and/or response generalization (Shalev et al, 2002) (Figure 2). Post hoc differences and the time course (30-min intervals) of yohimbine-induced reinstatement are provided in Figure 2. Analysis of Fos quantification (Figure 2) included the between-subjects factor of yohimbine dose and the withinsubjects factor of the mPFC region (ventral, dorsal). ANOVA revealed significant effects of yohimbine dose $\left(\mathrm{F}_{1,12}=17.4, p<0.01\right)$, mPFC region $\left(\mathrm{F}_{1,12}=32.5, p<0.01\right)$, and yohimbine dose $\times \mathrm{mPFC}$ region $\left(\mathrm{F}_{1,12}=35.7, p<0.01\right)$. The significant interaction reflects a stronger effect of yohimbine on Fos-IR induction in the dorsal vs the ventral mPFC. This conclusion is qualitatively confirmed in a small sample ( $n=3$ per group) in which we assessed the percentage of double-labeled Fos-NeuN neurons in the ventral and dorsal mPFCs after water or yohimbine injections (dorsal mPFC: water: $3.8 \pm 1.1 \%$, yohimbine: $24.6 \pm 2.1 \%$; ventral mPFC: water: $4.0 \pm 1.0 \%$, yohimbine: $11.5 \pm 1.3 \%$ ) (Figure 2).

Experiment 1 b. Systemic SCH23390 injections blocked yohimbine-induced reinstatement of lever responding and yohimbine-induced Fos induction in the dorsal and ventral mPFCs. As in experiment 1a, yohimbine-induced Fos induction was more pronounced in the dorsal than in the ventral mPFC (Figure 3). Behavioral data (active lever presses) were analyzed using the between-subjects factors of yohimbine dose $(0,2 \mathrm{mg} / \mathrm{kg})$ and $\mathrm{SCH} 23390$ dose $(0,10 \mu \mathrm{g} /$ $\mathrm{kg})$. ANOVA revealed significant effects of yohimbine dose $\left(\mathrm{F}_{1,22}=17.9, p<0.01\right)$, SCH23390 dose $\left(\mathrm{F}_{1,22}=12.9\right.$, $p<0.01)$, and yohimbine dose $\times \mathrm{SCH} 23390$ dose $\left(\mathrm{F}_{1,22}=10.3, p<0.01\right)$. Post hoc differences and the time course (30-min intervals) of yohimbine-induced reinstatement are provided in Figure 3. Analysis of Fos quantification included the between-subjects factors of yohimbine dose and SCH23390 dose, and the within-subjects factor of the $\mathrm{mPFC}$ region (ventral, dorsal). ANOVA revealed significant effects of yohimbine dose $\left(\mathrm{F}_{1,22}=23.8, p<0.01\right)$, SCH23390 dose $\left(\mathrm{F}_{1,22}=16.4, p<0.01\right)$, mPFC region $\left(\mathrm{F}_{1,22}=27.9, \quad p<0.01\right), \quad \mathrm{SCH} 23390$ dose $\times \mathrm{mPFC}$ region $\left(\mathrm{F}_{1,22}=8.3, p<0.01\right)$, yohimbine dose $\times \mathrm{SCH} 23390$ dose $\left(\mathrm{F}_{1,22}=10.8, \quad p<0.01\right)$, yohimbine dose $\times \mathrm{mPFC}$ region $\left(\mathrm{F}_{1,22}=5.4, p<0.05\right)$, and yohimbine dose $\times \mathrm{SCH} 23390$ dose $\times$ mPFC region $\left(F_{1,22}=35.7, p<0.01\right)$. These significant interactions reflect (1) a stronger effect of yohimbine on Fos induction in the dorsal vs the ventral mPFC, (2) a stronger attenuation of yohimbine-induced Fos expression by SCH23390 in the dorsal vs the ventral MPFC, and 
a Total lever presses

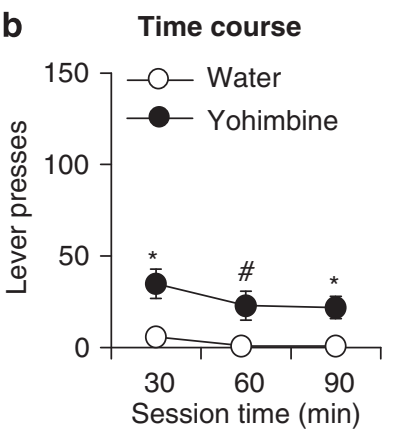

C Fos-IR quantification

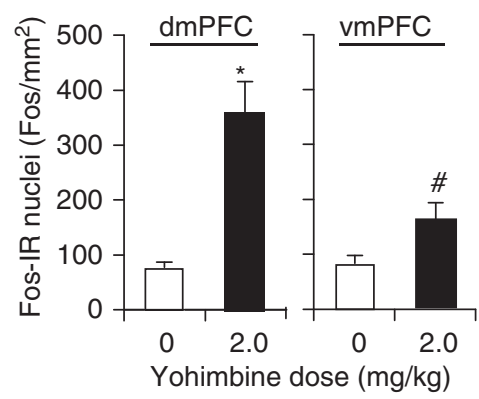

d

Fos-IR and Fos-IR+NeuN
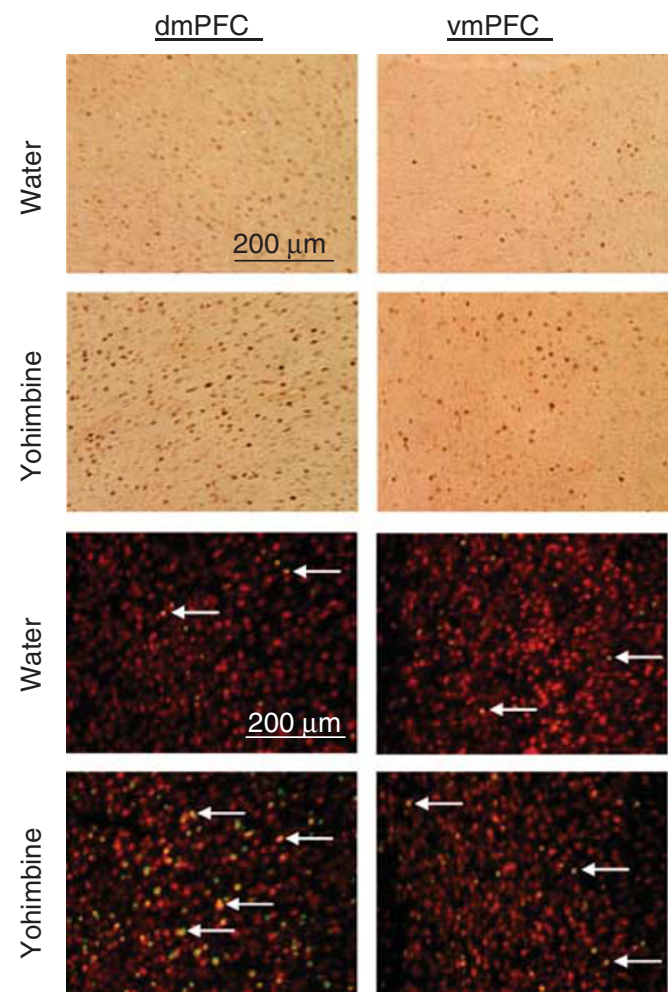

Figure 2 Effect of systemic injections of yohimbine $(2 \mathrm{mg} / \mathrm{kg})$ or water (vehicle) on reinstatement of lever responding and Fos induction in the dorsal and ventral mPFCs. $(a, b)$ Mean \pm SEM number of active and inactive lever presses after systemic injections of water or yohimbine (total per 90-min and 30-min time course ( $n=7$ per group). (c) Mean \pm SEM number of Fos-IR nuclei (per $\mathrm{mm}^{2}$ ) in the dorsal (left) and ventral (right) mPFCs $2 \mathrm{~h}$ after systemic injections of water or yohimbine. (d) Representative pictures of Fos-IR nuclei or Fos-NeuN double labeling in the dorsal (left column) and ventral (right column) mPFCs from rats pretreated with water (top row) or yohimbine (bottom row). Different from the water condition, ${ }^{*} p<0.01,{ }^{\#} p<0.05$.

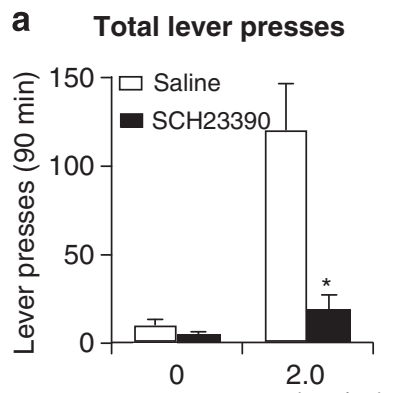

b

Time course

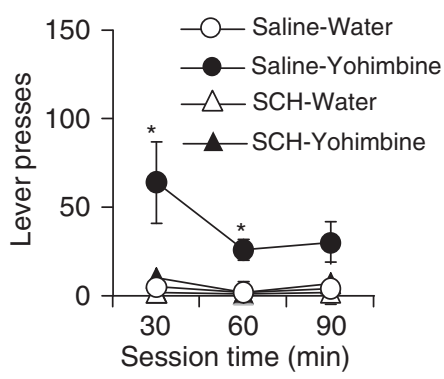

C Fos-IR quantification
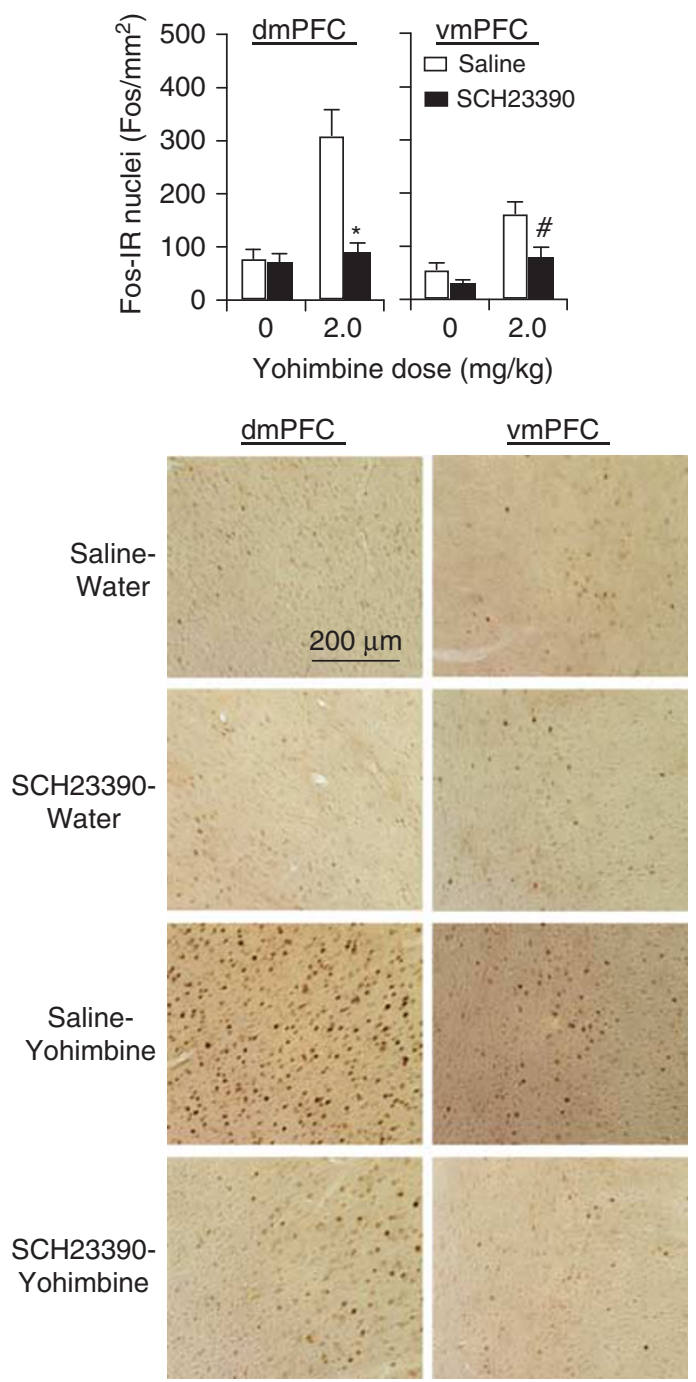

Figure 3 Effect of systemic injections of $\mathrm{SCH} 23390(10 \mu \mathrm{g} / \mathrm{kg})$ on yohimbine-induced reinstatement of lever responding and Fos induction in the dorsal and ventral mPFCs. (a, b) Mean \pm SEM number of active lever responses after systemic injections of saline or $\mathrm{SCH} 23390$, followed by water or yohimbine (total per 90-min and 30-min time course ( $n=6-7$ per group). (c) Mean \pm SEM number of Fos-IR nuclei (per $\mathrm{mm}^{2}$ ) in the dorsal (left) and ventral (right) mPFCs $2 \mathrm{~h}$ after systemic injections of saline or $\mathrm{SCH} 23390$, followed by water or yohimbine. (d) Representative pictures of Fos-IR nuclei in the dorsal (left column) and ventral (right column) mPFCs from rats pretreated with saline-water (row I), SCH23390-water (row 2), saline-yohimbine (row 3), or SCH23390-yohimbine (row 4). Different from the water condition, ${ }^{*} p<0.01,{ }^{\#} p<0.05$. dmPFC and vmPFC, dorsal and ventral mPFC, respectively. 
(3) a modest reduction by $\mathrm{SCH} 23390$ of basal Fos expression in the ventral but not in the dorsal mPFC (the 0 dose of the yohimbine condition). Neither yohimbine nor SCH23390 had an effect on inactive lever responding (data not shown). Post hoc differences are indicated in Figure 3.

\section{Experiment 2: Effect of Dorsal and Ventral mPFC Injections of SCH23390 on Yohimbine-Induced Reinstatement}

Dorsal mPFC. Dorsal mPFC SCH23390 injections decreased yohimbine-induced reinstatement of lever responding (Figure 4). Statistical analysis included the between-subjects factor of SCH 23390 dose ( 0.5 or $1 \mu \mathrm{g} / \mathrm{side})$ and the within-subjects factors of pretreatment condition (vehicle, SCH23390 (0.5 or $1 \mu \mathrm{g} /$ side $)$ ), and yohimbine dose $(0,2 \mathrm{mg})$. ANOVA revealed significant effects of yohimbine dose $\left(\mathrm{F}_{1,18}=58.9, p<0.01\right)$, pretreatment condition $\left(\mathrm{F}_{1,18}=\right.$ 20.8, $p<0.01)$, and pretreatment condition $\times$ yohimbine dose $\left(\mathrm{F}_{1,18}=25.7, p<0.01\right)$. This mixed AVOVA also revealed that the effect of $\mathrm{SCH} 23390$ dose was not significant $(p>0.1)$, because both the low $(0.5 \mu \mathrm{g} / \mathrm{side})$ and the high $(1.0 \mu \mathrm{g} / \mathrm{side})$ dose decreased yohimbineinduced reinstatement to a similar degree. Post hoc differences and the time course of yohimbine-induced reinstatement are indicated in Figure 4. Neither yohimbine nor SCH23390 had an effect on inactive lever responding (data not shown).

Ventral mPFC. Ventral mPFC SCH23390 injections $(1 \mu \mathrm{g} / \mathrm{site})$ had no effect on yohimbine-induced reinstatement of lever responding (Figure 4). ANOVA revealed significant effects of $y$ ohimbine dose $\left(\mathrm{F}_{1,8}=62.7, p<0.01\right)$ but not of SCH23390 dose or SCH23390 dose $\times$ yohimbine dose $(p>0.1)$. Neither yohimbine nor SCH23390 had an effect on inactive lever responding (data not shown).

\section{Experiment 3: Effect of Dorsal mPFC Injections of SCH23390 on Food Self-Administration, and Pellet-Priming- and Cue-Induced Reinstatement}

Experiment 3a: pellet self-administration. Injections of SCH23390 in the dorsal mPFC had no effect on pellet intake or timeout responses on the active lever during training ( $p$-values $>0.1$; Figure 5).

Experiment 3b: pellet-priming-induced reinstatement. Injections of SCH23390 in the dorsal mPFC decreased pellet-priming-induced reinstatement of active lever responding (Figure 5). Statistical analysis included the withinsubjects factors of SCH23390 dose ( 0 or $1 \mu \mathrm{g} /$ side) and lever (active, inactive). ANOVA revealed significant effects of SCH23390 dose $\left(\mathrm{F}_{1,9}=11.2, p<0.01\right)$, lever $\left(\mathrm{F}_{1,9}=66.1\right.$, $p<0.01)$, and SCH23390 dose $\times$ lever $\left(\mathrm{F}_{1,9}=8.9, p<0.01\right)$. Post hoc differences and the time course (60-min intervals) of the effect of SCH23390 on pellet-priming-induced reinstatement are indicated in Figure 5.

Experiment 3c: cue-induced reinstatement. Injections of SCH23390 in the dorsal mPFC had no effect on cue-induced a
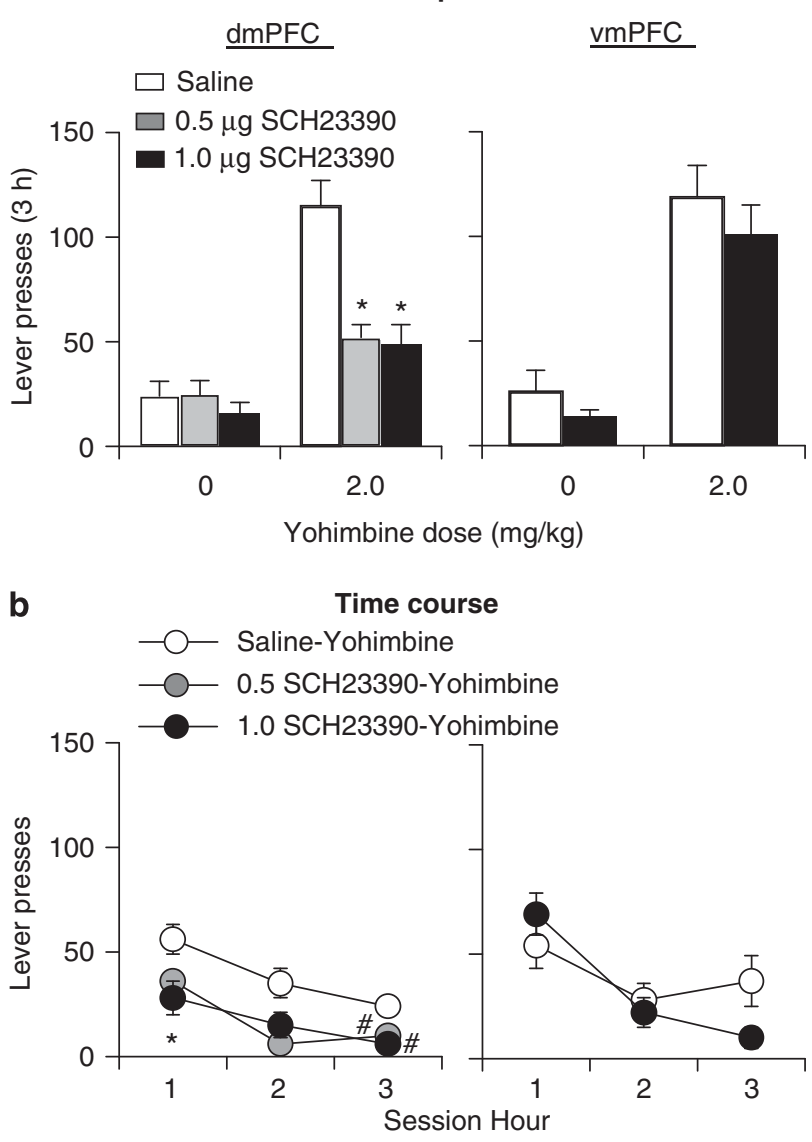

C Cannula placements

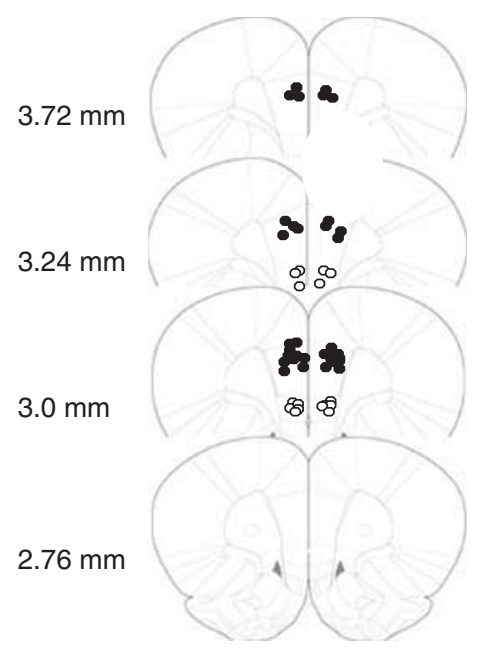

Figure 4 Effect of dorsal or ventral mPFC injections of SCH23390 (0.5 or $\mid \mu g / s i d e)$ on yohimbine-induced reinstatement. (a, b) Mean \pm SEM number of active lever responses after dorsal or ventral mPFC injections of saline or $\mathrm{SCH} 23390$, followed by systemic water or yohimbine injections (total per $3-h$ and $1-h$ time course; $n=8-12$ per SCH23390 dose). (c) Approximate placements of the tip of the injectors in the dorsal (closed circles) and ventral (open circles) mPFCs of rats in panels a, b; numbers refer to distance from the bregma (Paxinos and Watson, 2005). Different from the water condition, ${ }^{*} p<0.01,{ }^{\#} p<0.05$. dmPFC and vmPFC, dorsal and ventral mPFC, respectively. 
reinstatement of lever responding (Figure 5). Statistical analysis included the within-subjects factors of SCH23390 dose (0 or $1 \mu \mathrm{g} / \mathrm{side}$ ) and lever (active, inactive). ANOVA revealed significant effects of lever $\left(\mathrm{F}_{1,9}=48.0, p<0.01\right)$, but not of SCH23390 dose or SCH23390 dose $\times$ lever $(p>0.1)$.
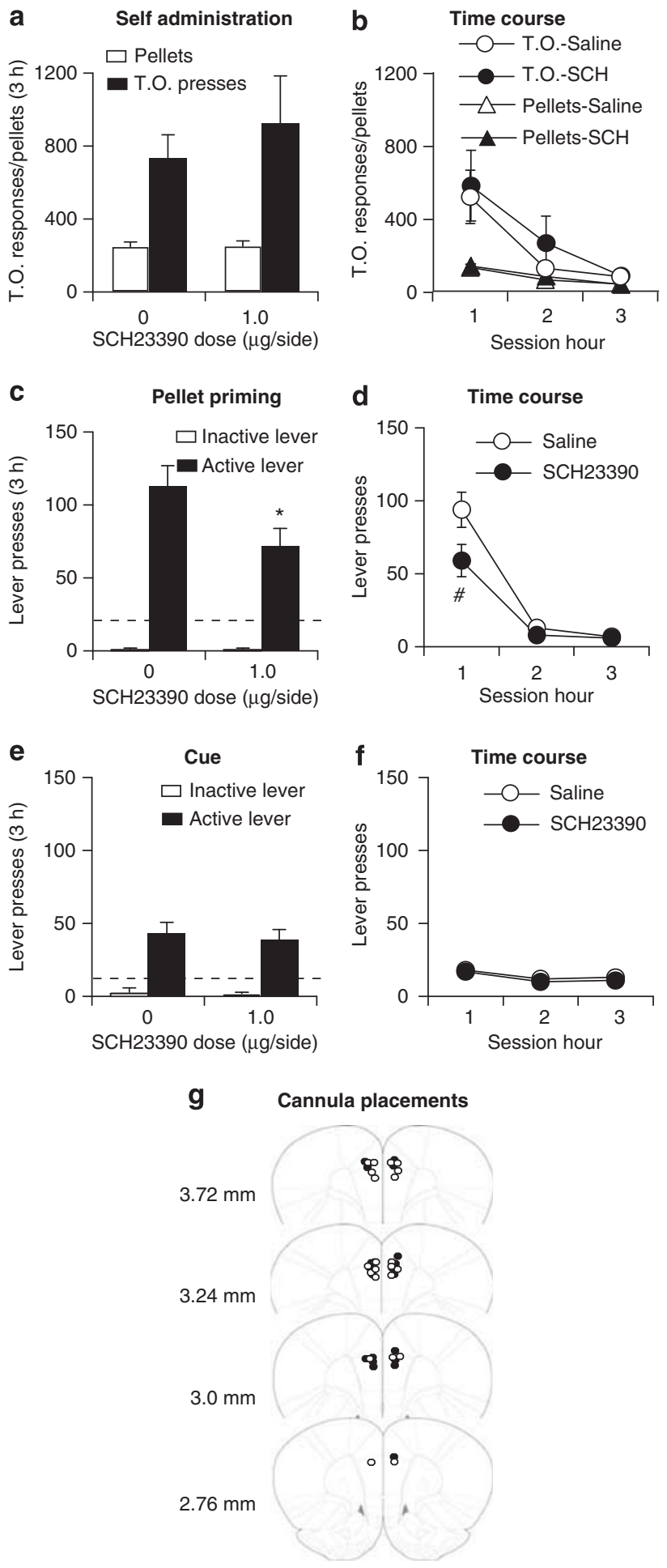

Experiment 4: Effect of dorsal mPFC Injections of the 5HT2c Agonist MK212 and the 5-HT2a Antagonist M100907 on Yohimbine-Induced Reinstatement

Experiment 4a: MK212. Dorsal mPFC injections of the 5-HT2c agonist MK212 had no effect on yohimbine-induced reinstatement of active lever responding. The mean \pm SEM number of active and inactive lever presses for the last 3 extinction sessions before the first test was $15.0 \pm 1.6$ and $1.8 \pm 1.4$, respectively. During tests for yohimbine-induced reinstatement, the number of active and inactive lever presses under vehicle and MK212 pretreatment conditions was $125.1 \pm 21.4$ and $117.0 \pm 23.0$ vs $27.2 \pm 9.5$ and $32.1 \pm 15.0$, respectively. Statistical analysis included the within-subject factors of MK212 dose $(0$ or $0.1 \mu \mathrm{g} / \mathrm{side})$ and lever (active, inactive). ANOVA revealed significant effects of lever $\left(\mathrm{F}_{1,9}=22.9, p<0.01\right)$, but not of MK212 dose or MK212 dose $\times$ lever $(p>0.1)$. The reasons for increased inactive lever responding after yohimbine injections, which was not observed in experiments 1-2 and in our previous work, are unknown.

Experiment 4b: M100907. Dorsal mPFC injections of the 5-HT2a antagonist M100907 had no effect on yohimbineinduced reinstatement of active lever responding. The mean \pm SEM number of active and inactive lever presses for the last 3 extinction sessions before the first test was $16 \pm 2$ and $1 \pm 1$, respectively. During tests for yohimbineinduced reinstatement, the number of active and inactive lever presses under vehicle and M100907 pretreatment conditions was $86 \pm 12$ and $90 \pm 8$ vs $18 \pm 10$ and $8 \pm 3$, respectively. Statistical analysis included the within-subject factors of M100907 dose (0 or $0.3 \mu \mathrm{g} / \mathrm{side}$ ) and lever (active, inactive). ANOVA revealed significant effects of lever $\left(\mathrm{F}_{1,8}=76.7, p<0.01\right)$, but not of M100907 dose or M100907 dose $\times$ lever $(p>0.1)$.

\section{DISCUSSION}

We studied the role of D1-family receptors in the reinstatement of high-fat food seeking induced by the anxiogenic drug yohimbine, which induces stress-like

Figure 5 Effect of dorsal mPFC injections of SCH23390 (I.0 $\mu \mathrm{g} / \mathrm{side})$ on food pellet self-administration, and pellet-priming- and cue-induced reinstatement. ( $a, b)$ Pellet self-administration: Mean \pm SEM number of $35 \%$ fat pellets earned and timeout responses after dorsal mPFC injections of saline or $\mathrm{SCH} 23390$ (total per 3-h and I-h time course, $n=10$ ). (c, d) Pellet-priming-induced reinstatement: Mean \pm SEM number of active and inactive lever responses after dorsal mPFC injections of saline or $\mathrm{SCH} 23390$ during testing $(n=10)$. The priming manipulation was noncontingent delivery of three pellets, every $20 \mathrm{~s}$, at the onset of the test session. (e, f) Cue-induced reinstatement: Mean \pm SEM number of active and inactive lever responses after dorsal mPFC injections of saline or $\mathrm{SCH} 23390$ during testing $(n=10)$. During testing, lever presses led to contingent presentations of the tone-light cue that was paired with pellet delivery during the training phase and was omitted during the extinction phase. (g) Approximate placements of the tip of the injectors in the dorsal $\mathrm{mPFC}$ for the data in panels a- $d$ (closed circles) and in panels e and $\mathrm{f}$ (open circles); numbers refer to distance from the bregma (Paxinos and Watson, 2005). Different from the saline condition, ${ }^{*} p<0.01,{ }^{\#} p<0.05$. Dashed horizontal line: mean number of active lever presses during the last three extinction sessions before testing. 
responses in both humans and nonhumans (Redmond and Huang, 1979). Yohimbine-induced reinstatement was associated with strong Fos (a neuronal activity marker) induction in the dorsal mPFC and weaker Fos induction in the ventral mPFC. The effect of yohimbine on reinstatement of food seeking and mPFC Fos induction was blocked by systemic SCH23390 injections, suggesting a role of mPFC D1-family receptors in yohimbine-induced reinstatement. This possibility was confirmed by demonstrating that dorsal but not ventral mPFC SCH23390 injections attenuated this reinstatement. These data established a causal role of dorsal mPFC D1-family receptors in yohimbine-induced reinstatement of food seeking.

In a follow-up experiment on the behavioral specificity of mPFC SCH23390 injections on reinstatement of food seeking, we found that D1-family receptor blockade decreased pellet-priming-induced reinstatement but had no effect on cue-induced reinstatement or on ongoing pellet self-administration. These data suggest that mechanisms of pellet-priming-induced reinstatement and cue-induced reinstatement are not identical, and support the notion that mechanisms of ongoing food intake and relapse to food seeking are dissociable (Nair et al, 2009a). In another follow-up experiment on the pharmacological specificity of SCH23390, we found that MK212 or M100907 dorsal mPFC injections had no effect on yohimbine-induced reinstatement. These data suggest that SCH23390 effects on yohimbine-induced reinstatement are not due to its actions on 5-HT2c or 5-HT2a receptors (Millan et al, 2001; Neumeyer et al, 2003).

\section{Role of mPFC Dopamine D1-Family Receptors in Reinstatement of Food Seeking}

A main finding in our study is that dorsal mPFC SCH23390 injections decreased reinstatement of food seeking induced by both yohimbine and pellet priming. It is unlikely that these effects are due to nonspecific disruption of lever responding, because $\mathrm{SCH} 23390$ injections had no effect on a much higher response rate for the food pellets during training (Figure 5a). Thus, our data suggest a general role of dorsal mPFC dopamine D1-family receptors in relapse to food seeking, as assessed in the reinstatement procedure. One caveat of this conclusion is that dorsal mPFC SCH23390 had no effect on discrete-cue-induced reinstatement. However, these negative data should be interpreted with caution, because the magnitude of responding in the discrete-cue-induced reinstatement tests was much lower than in the yohimbine- or pellet-priming-induced reinstatement tests. Thus, our cue-induced reinstatement manipulation may not be sufficiently sensitive to reliably detect effects of pharmacological manipulations on this reinstatement.

It is also unknown whether dorsal mPFC D1-family receptors have a role in other forms of relapse to food seeking, including the time-dependent increases in cueinduced reinstatement (incubation of food seeking) (Grimm et al, 2002, 2005), or reinstatement induced by contextual (Bossert et al, 2006; Hamlin et al, 2006) or discriminative (Baptista et al, 2004) food cues. In this regard, studies using drug rewards indicate that the mechanisms of reinstatement induced by discrete vs contextual drug cues only partially overlap (Crombag et al, 2008; Feltenstein and See, 2008). In addition, we found that reversibly inactivating the ventral but not the dorsal mPFC with a muscimol+baclofen mixture decreases the time-dependent increases in cueinduced cocaine seeking, as assessed in a single extinction test (Koya et al, 2009).

Our finding on the effect of dorsal mPFC SCH23390 injections on pellet-priming-induced reinstatement of food seeking is consistent with that of Sun and Rebec (2005). However, these findings are different from those of McFarland and Kalivas (2001) who reported that dorsal mPFC inactivation with muscimol + baclofen had no effect on pellet-priming-induced reinstatement. In interpreting these different findings it should be noted that there are several other examples in drug reinstatement studies in which the effect of pharmacological antagonism of D1-family receptors does not mimic the behavioral effects of muscimol + baclofen inactivation (Bossert et al, 2005). For example, McFarland and Kalivas (2001) reported that muscimol + baclofen inactivation of the nucleus accumbens core, but not shell, attenuates cocaine-priming-induced reinstatement. In contrast, Anderson et al (2003) reported that SCH23390 injections into the nucleus accumbens shell, but not core, attenuate this reinstatement.

\section{Mechanisms Underlying the Role of Dorsal mPFC Dopamine in Yohimbine-Induced Reinstatement: A Neuropsychological Perspective}

A question for future research is the identification of the neuropsychological processes or mechanisms underlying the role of dorsal mPFC dopamine in yohimbine-induced reinstatement in particular and more generally in stressinduced reinstatement. Below, we speculate on the putative role of four potential mechanisms related to mPFC's role in response to satiety signals, behavioral inhibition, stress responses, and reward seeking.

Food Satiety. In food-restricted rats, exposure to palatable food increases mPFC dopamine release. This effect is reduced by selective satiety (a brief previous exposure to the same but not different palatable food before a second exposure to the food), suggesting a role of dorsal mPFC dopamine in food satiety mechanisms (Ahn and Phillips, 1999, 2002). However, it is unlikely that the modulation of SCH23390 of mPFC-dependent satiety mechanisms mediates its effect on yohimbine-induced reinstatement, because dorsal mPFC SCH23390 injections had no effect on ongoing pellet self-administration.

Behavioral Inhibition. We previously suggested that stress may provoke relapse by interfering with a putative behavioral inhibition system the function of which is to stop ongoing activity when reinforcers are not available (Highfield et al, 2000b), as, eg, during extinction training (Bouton and Swartzentruber, 1991; Gray, 1987; Pavlov, 1927). Some support for this hypothesis is the finding that repeated exposure to footshock or yohimbine during the extinction phase increases resistance to extinction of drug seeking (Highfield et al, 2000a; Kupferschmidt et al, 2009). The 'behavioral inhibition' hypothesis might be relevant to the present findings, because there is evidence that mPFC 
lesions interfere with behavioral responses in learning tasks assessing behavioral inhibition (Kolb, 1984). However, this hypothesis is not supported by the present data or previous data mentioned above (Kalivas and McFarland, 2003), because a main prediction of the behavioral inhibition hypothesis would be that interference with MPFC function in the absence of stress exposure would reinstate reward seeking, mimicking the effect of stressors.

Stress Responses. Dorsal mPFC SCH23390 injections may decrease yohimbine-induced reinstatement because they decrease the manifestation of physiological and psychological stress states induced by yohimbine. In this regard, tailpinch-stress-induced secretion of the stress hormone corticosterone (Selye, 1936) is correlated with tail-pinchinduced increases in MPFC dopamine levels (Sullivan and Gratton, 1998). In addition, dorsal mPFC lesions decrease stress-induced corticosterone secretion and gastric ulcer development (Sullivan and Gratton, 1999). Yohimbine increases corticosterone secretion in both rats (Marinelli et al, 2007) and monkeys (Lee et al, 2004). However, it is unlikely that this effect and its potential modulation by dorsal mPFC dopamine are involved in yohimbine-induced reinstatement because the effects of yohimbine on corticosterone secretion can be dissociated pharmacologically: the CRF1 receptor antagonist antalarmin blocks yohimbineinduced reinstatement of alcohol seeking but has no effect on yohimbine-induced corticosterone secretion (Marinelli et al, 2007). In addition, stress-induced corticosterone secretion does not mediate stress-induced reinstatement of drug seeking (Erb et al, 1998; Shaham et al, 1997), a phenomenon critically dependent on dorsal mPFC dopamine (Capriles et al, 2003; McFarland et al, 2004). However, it is possible that blockade of D1-family receptors ameliorates the impact of stress-related psychological processes that are dependent on intact $\mathrm{mPFC}$ (eg, increasing the perception of control over stress experience; Maier and Watkins, 2005), which in turn leads to decreased stressinduced reinstatement.

Reward Seeking. The effect of dorsal mPFC SCH23390 injections on yohimbine-induced reinstatement might be due to interference with the normal functioning of the putative 'final common pathway' glutamatergic projection from the dorsal mPFC to the accumbens core that mediates reinstatement of cocaine seeking induced by drug priming, discrete cues, and footshock stress; activation of this pathway is critically dependent on mPFC dopamine transmission (Feltenstein and See, 2008; Kalivas and McFarland, 2003). The 'final common pathway' hypothesis can account for similar effects of SCH23390 injections on both yohimbine- and pellet-priming-induced reinstatement. However, a prediction of this hypothesis is that $\mathrm{SCH} 23390$ injections should also attenuate discrete-cue-induced reinstatement, which we did not observe.

\section{Concluding Remarks}

Since 2004 (Lee et al, 2004; Shepard et al, 2004), yohimbine has been used as a pharmacological stressor in many reinstatement studies with food and drug rewards
(Feltenstein and See, 2008; Nair et al, 2009a), but the brain sites involved in this effect have not been identified. In this study, we demonstrate a critical role of dorsal but not ventral mPFC dopamine D1-family receptors in yohimbineinduced reinstatement, and also provide evidence for the role of these receptors in pellet-priming-induced reinstatement. The results of this study and our previous work on relapse to food seeking during dieting may have implications for medication development (Nair et al, 2009a).

Historically, dietary treatments have primarily been developed based on their effects on physiological mechanisms that regulate ongoing food intake or food metabolism (Bray and Greenway, 2007). Yet, it has been known for many years that the physiological states of hunger and satiety are often dissociable from human feeding behaviors. Instead, these behaviors are to a significant extent under the control of external stimuli, such as stress and food cues (Schachter, 1968, 1974). A common theme in our studies on reinstatement of food seeking is that our pharmacological manipulations have dissociable effects on reinstatement of food seeking vs food intake during self-administration training (Nair et al, 2009b). Thus, the use of the reinstatement procedure allows for the identification of pharmacological agents that can prevent relapse to food by targeting the impact of stress or food cues on food-seeking behaviors in humans. These putative potential medications may not reach clinical development if the targeted preclinical outcome is reduction of ongoing food intake in rodents.

\section{ACKNOWLEDGEMENTS}

The work was supported by the Intramural Research Program of the National Institute on Drug Abuse. We thank Drs Bruce Hope and Eisuke Koya for their help with the immunohistochemical assays and image analyses, and Dr Kenner Rice for synthesizing M100907 for experiment 4.

\section{DISCLOSURE}

The authors state no conflict of interest.

\section{REFERENCES}

Ahn S, Phillips AG (1999). Dopaminergic correlates of sensoryspecific satiety in the medial prefrontal cortex and nucleus accumbens of the rat. J Neurosci 19: RC29.

Ahn S, Phillips AG (2002). Modulation by central and basolateral amygdalar nuclei of dopaminergic correlates of feeding to satiety in the rat nucleus accumbens and medial prefrontal cortex. J Neurosci 22: 10958-10965.

Alleweireldt AT, Hobbs RJ, Taylor AR, Neisewander JL (2006). Effects of SCH-23390 infused into the amygdala or adjacent cortex and basal ganglia on cocaine seeking and self-administration in rats. Neuropsychopharmacology 31: 363-374.

Anderson SM, Bari AA, Pierce RC (2003). Administration of the D1-like dopamine receptor antagonist SCH-23390 into the medial nucleus accumbens shell attenuates cocaine priming-induced reinstatement of drug-seeking behavior in rats. Psychopharmacology 168: 132-138.

Avena NM, Rada P, Hoebel BG (2008). Evidence for sugar addiction: behavioral and neurochemical effects of intermittent, excessive sugar intake. Neurosci Biobehav Rev 32: 20-39. 
Bachtell RK, Whisler K, Karanian D, Self DW (2005). Effects of intra-nucleus accumbens shell administration of dopamine agonists and antagonists on cocaine-taking and cocaine-seeking behaviors in the rat. Psychopharmacology 183: 41-53.

Baker A, Steinwald H, Bouton M (1991). Contexual conditioning and reinstatement of extinguished instrumental responding. Quarterly J Exp Psychol 43B: 199-218.

Baptista MA, Martin-Fardon R, Weiss F (2004). Preferential effects of the metabotropic glutamate 2/3 receptor agonist LY379268 on conditioned reinstatement versus primary reinforcement: comparison between cocaine and a potent conventional reinforcer. J Neurosci 24: 4723-4727.

Bing G, Chen S, Zhang Y, Hillman D, Stone EA (1992). Noradrenergic-induced expression of c-fos in rat cortex: neuronal localization. Neurosci Lett 140: 260-264.

Bing GY, Filer D, Miller JC, Stone EA (1991). Noradrenergic activation of immediate early genes in rat cerebral cortex. Brain Res Mol Brain Res 11: 43-46.

Boggiano MM, Artiga AI, Pritchett CE, Chandler-Laney PC, Smith ML, Eldridge AJ (2007). High intake of palatable food predicts binge-eating independent of susceptibility to obesity: an animal model of lean $v s$ obese binge-eating and obesity with and without binge-eating. Int J Obes 31: 1357-1367.

Bossert JM, Ghitza UE, Lu L, Epstein DH, Shaham Y (2005). Neurobiology of relapse to heroin and cocaine seeking: an update and clinical implications. Eur J Pharmacol 526: 36-50.

Bossert JM, Poles GC, Sheffler-Collins SI, Ghitza UE (2006). The mGluR2/3 agonist LY379268 attenuates context- and discrete cue-induced reinstatement of sucrose seeking but not sucrose self-administration in rats. Behav Brain Res 173: $148-152$.

Bossert JM, Poles GC, Wihbey KA, Koya E, Shaham Y (2007). Differential effects of blockade of dopamine D1-family receptors in nucleus accumbens core or shell on reinstatement of heroin seeking induced by contextual and discrete cues. J Neurosci 27: 12655-12663.

Bossert JM, Wihbey KA, Pickens CL, Nair SG, Shaham Y (2009). Role of dopamine $\mathrm{D}(1)$-family receptors in dorsolateral striatum in context-induced reinstatement of heroin seeking in rats. Psychopharmacology 206: 51-60.

Bouton ME, Swartzentruber D (1991). Sources of relapse after extinction in Pavlovian and instrumental learning. Clin Psychol Rev 11: 123-140.

Bray GA, Greenway FL (2007). Pharmacological treatment of the overweight patient. Pharmacol Rev 59: 151-184.

Bremner JD, Krystal JH, Southwick SM, Charney DS (1996a). Noradrenergic mechanisms in stress and anxiety: I. Preclinical studies. Synapse 23: 28-38.

Bremner JD, Krystal JH, Southwick SM, Charney DS (1996b). Noradrenergic mechanisms in stress and anxiety: II. Clinical studies. Synapse 23: 39-51.

Briggs CA, Pollock NJ, Frail DE, Paxson CL, Rakowski RF, Kang $\mathrm{CH}$ et al (1991). Activation of the 5-HT1C receptor expressed in Xenopus oocytes by the benzazepines SCH 23390 and SKF 38393. Br J Pharmacol 104: 1038-1044.

Brown ZJ, Tribe E, D'ouza N A, Erb S (2009). Interaction between noradrenaline and corticotrophin-releasing factor in the reinstatement of cocaine seeking in the rat. Psychopharmacology (Berl) 203: 121-130.

Byrne S, Cooper Z, Fairburn C (2003). Weight maintenance and relapse in obesity: a qualitative study. Int J Obes Relat Metab Disord 27: 955-962.

Capriles N, Rodaros D, Sorge RE, Stewart J (2003). A role for the prefrontal cortex in stress- and cocaine-induced reinstatement of cocaine seeking in rats. Psychopharmacology 168: $66-74$.

Chaudhri N, Sahuque LL, Janak PH (2009). Ethanol seeking triggered by environmental context is attenuated by blocking dopamine D1 receptors in the nucleus accumbens core and shell in rats. Psychopharmacology 207: 303-314.

Cifani C, Polidori C, Melotto S, Ciccocioppo R, Massi M (2009). A preclinical model of binge eating elicited by yo-yo dieting and stressful exposure to food: effect of sibutramine, fluoxetine, topiramate, and midazolam. Psychopharmacology 204: 113-125.

Cippitelli A, Damadzic R, Hansson AC, Singley E, Sommer WH, Eskay $\mathrm{R}$ et al (2010). Neuropeptide Y (NPY) suppresses yohimbine-induced reinstatement of alcohol seeking. Psychopharmacology 208: 417-426.

Colantuoni C, Rada P, McCarthy J, Patten C, Avena NM, Chadeayne A et al (2002). Evidence that intermittent, excessive sugar intake causes endogenous opioid dependence. Obes Res 10: 478-488.

Corwin RL, Buda-Levin A (2004). Behavioral models of binge-type eating. Physiol Behav 82: 123-130.

Crombag H, Bossert JM, Koya E, Shaham Y (2008). Contextinduced relapse to drug seeking: a review. Trans $R$ Soc Lond $B$ Biol Sci 363: 3233-3243.

Curran T, Morgan JI (1995). Fos: an immediate-early transcription factor in neurons. J Neurobiol 26: 403-412.

Davis WM, Smith SG (1976). Role of conditioned reinforcers in the initiation, maintenance and extinction of drug-seeking behavior. Pavlovian J Biol Sci 11: 222-236.

De Vries TJ, de Vries W, Janssen MC, Schoffelmeer AN (2005). Suppression of conditioned nicotine and sucrose seeking by the cannabinoid-1 receptor antagonist SR141716A. Behav Brain Res 161: 164-168.

Deutch AY, Roth RH (1990). The determinants of stress-induced activation of the prefrontal cortical dopamine system. Prog Brain Res 85: 367-403.

Erb S, Shaham Y, Stewart J (1998). The role of corticotropinreleasing factor and corticosterone in stress- and cocaineinduced relapse to cocaine seeking in rats. $J$ Neurosci 18: 5529-5536.

Feltenstein MW, See RE (2006). Potentiation of cue-induced reinstatement of cocaine-seeking in rats by the anxiogenic drug yohimbine. Behav Brain Res 174: 1-8.

Feltenstein MW, See RE (2008). The neurocircuitry of addiction: an overview. Br J Pharmacol 154: 261-274.

Figlewicz DP, MacDonald Naleid A, Sipols AJ (2007). Modulation of food reward by adiposity signals. Physiol Behav 91: 473-478.

Filip M, Cunningham KA (2003). Hyperlocomotive and discriminative stimulus effects of cocaine are under the control of serotonin(2C) (5-HT(2C)) receptors in rat prefrontal cortex. J Pharmacol Exp Ther 306: 734-743.

Fletcher PJ, Rizos Z, Sinyard J, Tampakeras M, Higgins GA (2008). The 5-HT(2C) receptor agonist Ro60-0175 reduces cocaine selfadministration and reinstatement induced by the stressor yohimbine, and contextual cues. Neuropsychopharmacology 33: 1402-1412.

Floresco SB, McLaughlin RJ, Haluk DM (2008). Opposing roles for the nucleus accumbens core and shell in cue-induced reinstatement of food-seeking behavior. Neuroscience 154: 877-884.

Funk D, Li Z, Le AD (2006). Effects of environmental and pharmacological stressors on c-fos and corticotropin-releasing factor mRNA in rat brain: relationship to the reinstatement of alcohol seeking. Neuroscience 138: 235-243.

Ghitza UE, Gray SM, Epstein DH, Rice KC, Shaham Y (2006). The anxiogenic drug yohimbine reinstates palatable food seeking in a rat relapse model: a role of $\mathrm{CRF}(1)$ receptors. Neuropsychopharmacology 31: 2188-2196.

Ghitza UE, Nair SG, Golden SA, Gray SM, Uejima JL, Bossert JM et al (2007). Peptide YY3-36 decreases reinstatement of high-fat food seeking during dieting in a rat relapse model. J Neurosci 27: 11522-11532.

Gray JA (1987). The Psychology of Fear and Stress, 2 edn. Cambridge University Press: New York. 
Graybiel AM, Moratalla R, Robertson HA (1990). Amphetamine and cocaine induce drug-specific activation of the c-fos gene in striosome-matrix compartments and limbic subdivisions of the striatum. Proc Natl Acad Sci USA 87: 6912-6916.

Grilo CM, Shiffman S, Wing RR (1989). Relapse crises and coping among dieters. J Consult Clin Psychol 57: 488-495.

Grimm JW, Fyall AM, Osincup DP (2005). Incubation of sucrose craving: effects of reduced training and sucrose pre-loading. Physiol Behav 84: 73-79.

Grimm JW, Shaham Y, Hope BT (2002). Effect of the cocaine and sucrose withdrawal period on extinction behavior, cue-induced reinstatement and protein levels of the dopamine transporter and tyrosine hydroxylase in limbic and cortical areas in rats. Behav Pharmacol 13: 379-388.

Hagan MM, Chandler PC, Wauford PK, Rybak RJ, Oswald KD (2003). The role of palatable food and hunger as trigger factors in an animal model of stress induced binge eating. Int J Eat Disord 34: 183-197.

Hagan MM, Wauford PK, Chandler PC, Jarrett LA, Rybak RJ, Blackburn K (2002). A new animal model of binge eating: key synergistic role of past caloric restriction and stress. Physiol Behav 77: 45-54.

Hamlin AS, Blatchford KE, McNally GP (2006). Renewal of an extinguished instrumental response: neural correlates and the role of D1 dopamine receptors. Neuroscience 143: 25-38.

Herman CP, Polivy J (1975). Anxiety, restraint, and eating behavior. J Abnorm Psychol 84: 66-72.

Highfield D, Clements A, Shalev U, McDonald R, Featherstone R, Stewart $\mathrm{J}$ et al (2000a). Involvement of the medial septum in stress-induced relapse to heroin seeking in rats. Eur J Neurosci 12: $1705-1713$.

Highfield D, Clements A, Shalev U, McDonald RJ, Featherstone R, Stewart J et al (2000b). Involvement of the medial septum in stress-induced relapse to heroin seeking in rats. Eur J Neurosci 12: 1705-1713.

Holmberg G, Gershon S (1961). Autonomic and psychic effects of yohimbine hydrochloride. Psychopharmacologia 2: 93-106.

Horvitz JC, Ettenberg A (1988). Haloperidol blocks the responsereinstating effects of food reward: a methodology for separating neuroleptic effects on reinforcement and motor processes. Pharmacol Biochem Behav 31: 861-865.

Kalivas PW, McFarland K (2003). Brain circuitry and the reinstatement of cocaine-seeking behavior. Psychopharmacology 168: $44-56$.

Kolb B (1984). Functions of the frontal cortex of the rat: a comparative review. Brain Res 320: 65-98.

Koya E, Uejima JL, Wihbey KA, Bossert JM, Hope BT, Shaham Y (2009). Role of ventral medial prefrontal cortex in incubation of cocaine craving. Neuropharmacology 56(Suppl 1): 177-185.

Kramer FM, Jeffery RW, Forster JL, Snell MK (1989). Long-term follow-up of behavioral treatment for obesity: patterns of weight regain among men and women. Int J Obes 13: 123-136.

Kupferschmidt DA, Tribe E, Erb S (2009). Effects of repeated yohimbine on the extinction and reinstatement of cocaine seeking. Pharmacol Biochem Behav 91: 473-480.

Lang WJ, Gershon S (1963). Effects of psychoactive drugs on yohimbine induced responses in conscious dogs. A proposed screening procedure for anti-anxiety agents. Arch Int Pharmacodyn Ther 142: 457-472.

Le AD, Funk D, Harding S, Juzytsch W, Fletcher PJ (2009). The role of noradrenaline and 5-hydroxytryptamine in yohimbineinduced increases in alcohol-seeking in rats. Psychopharmacology 204: 477-488.

Lee B, Tiefenbacher S, Platt DM, Spealman RD (2004). Pharmacological blockade of alpha(2)-arenoceptors induces reinstatement of cocaine-seeking behavior in squirrel monkeys. Neuropsychopharmacology 29: 686-693.
Maier SF, Watkins LR (2005). Stressor controllability and learned helplessness: the roles of the dorsal raphe nucleus, serotonin, and corticotropin-releasing factor. Neurosci Biobehav Rev 29: 829-841.

Mantsch JR, Weyer A, Vranjkovic O, Beyer CE, Baker DA, Caretta H (2010). Involvement of noradrenergic neurotransmission in the stress- but not cocaine-induced reinstatement of extinguished cocaine-induced conditioned place preference in mice: role for beta-2 adrenergic receptors. Neuropsychopharmacology 35: 2165-2178.

Marinelli PW, Funk D, Juzytsch W, Harding S, Rice KC, Shaham Y et al (2007). The $\mathrm{CRF}(1)$ receptor antagonist antalarmin attenuates yohimbine-induced increases in operant alcohol self-administration and reinstatement of alcohol seeking in rats. Psychopharmacology 195: 345-355.

McFarland K, Davidge SB, Lapish CC, Kalivas PW (2004). Limbic and motor circuitry underlying footshock-induced reinstatement of cocaine-seeking behavior. J Neurosci 24: $1551-1560$

McFarland K, Kalivas PW (2001). The circuitry mediating cocaineinduced reinstatement of drug-seeking behavior. J Neurosci 21: 8655-8663.

McLaughlin RJ, Floresco SB (2007). The role of different subregions of the basolateral amygdala in cue-induced reinstatement and extinction of food-seeking behavior. Neuroscience 146: 1484-1494.

McMahon LR, Filip M, Cunningham KA (2001). Differential regulation of the mesoaccumbens circuit by serotonin 5-hydroxytryptamine $(5-\mathrm{HT}) 2 \mathrm{~A}$ and $5-\mathrm{HT} 2 \mathrm{C}$ receptors. J Neurosci 21 : 7781-7787.

Meil WM, See RE (1996). Conditioned cued recovery of responding following prolonged withdrawal from self-administered cocaine in rats: an animal model of relapse. Behav Pharmacol 7: 754-763.

Millan MJ, Newman-Tancredi A, Quentric Y, Cussac D (2001). The "selective" dopamine D1 receptor antagonist, SCH23390, is a potent and high efficacy agonist at cloned human serotonin2C receptors. Psychopharmacology (Berl) 156: 58-62.

Monti JM, Fernandez M, Jantos H (1990). Sleep during acute dopamine D1 agonist SKF 38393 or D1 antagonist SCH 23390 administration in rats. Neuropsychopharmacology 3: 153-162.

Nair SG, Adams-Deutsch T, Epstein DH, Shaham Y (2009a). The neuropharmacology of relapse to food seeking: methodology, main findings, and comparison with relapse to drug seeking. Prog Neurobiol 89: 18-45.

Nair SG, Adams-Deutsch T, Pickens CL, Smith DG, Shaham Y (2009b). Effects of the MCH1 receptor antagonist SNAP 94847 on high-fat food-reinforced operant responding and reinstatement of food seeking in rats. Psychopharmacology 205: 129-140.

Nair SG, Golden SA, Shaham Y (2008). Differential effects of the hypocretin 1 receptor antagonist SB 334867 on high-fat food self-administration and reinstatement of food seeking in rats. Br J Pharmacol 154: 406-416.

Neumeyer JL, Kula NS, Bergman J, Baldessarini RJ (2003). Receptor affinities of dopamine D1 receptor-selective novel phenylbenzazepines. Eur J Pharmacol 474: 137-140.

Pavlov IP (1927). Conditioned Reflexes. Oxford University Press: Oxford.

Paxinos G, Watson C (2005). The Rat Brain in Stereotaxic Coordinates, 5 edn. Elsevier Academic Press: Amsterdam.

Pentkowski NS, Duke FD, Weber SM, Pockros LA, Teer AP, Hamilton EC et al (2010). Stimulation of medial prefrontal cortex serotonin $2 \mathrm{C}(5-\mathrm{HT}(2 \mathrm{C}))$ receptors attenuates cocaineseeking behavior. Neuropsychopharmacology 35: 2037-2048.

Peterson CB, Mitchell JE (1999). Psychosocial and pharmacological treatment of eating disorders: a review of research findings. J Clin Psychol 55: 685-697.

Polivy J, Herman CP (1999). Distress and eating: why do dieters overeat? Int J Eat Disord 26: 153-164. 
Porter RH, Benwell KR, Lamb H, Malcolm CS, Allen NH, Revell DF et al (1999). Functional characterization of agonists at recombinant human 5-HT2A, 5-HT2B and 5-HT2C receptors in CHO-K1 cells. Br J Pharmacol 128: 13-20.

Ramos M, Goni-Allo B, Aguirre N (2005). Administration of SCH 23390 into the medial prefrontal cortex blocks the expression of MDMA-induced behavioral sensitization in rats: an effect mediated by 5 -HT2C receptor stimulation and not by D1 receptor blockade. Neuropsychopharmacology 30: 2180-2191.

Redmond DEJ, Huang YH (1979). Locus coeruleus and anxiety. Life Sci 25: 2149-2162.

Richards JK, Simms JA, Steensland P, Taha SA, Borgland SL, Bonci A et al (2008). Inhibition of orexin-1/hypocretin-1 receptors inhibits yohimbine-induced reinstatement of ethanol and sucrose seeking in Long-Evans rats. Psychopharmacology 199: 109-117.

Robertson HA, Peterson MR, Murphy K, Robertson GS (1989). D1-dopamine receptor agonists selectively activate striatal c-fos independent of rotational behaviour. Brain Res 503: 346-349.

Sanchez CJ, Bailie TM, Wu WR, Li N, Sorg BA (2003). Manipulation of dopamine d1-like receptor activation in the rat medial prefrontal cortex alters stress- and cocaine-induced reinstatement of conditioned place preference behavior. Neuroscience 119: 497-505.

Schachter S (1968). Obesity and eating. Internal and external cues differentially affect the eating behavior of obese and normal subjects. Science 161: 751-756.

Schachter S (1974). Appetite regulation in obese subjects. Horm Metab Res (Suppl 4): 88-93.

Schreiber R, Brocco M, Audinot V, Gobert A, Veiga S, Millan MJ (1995). (1-(2,5-dimethoxy-4 iodophenyl)-2-aminopropane)-induced head-twitches in the rat are mediated by 5-hydroxytryptamine (5-HT) 2A receptors: modulation by novel 5-HT2A/ 2C antagonists, D1 antagonists and 5-HT1A agonists. J Pharmacol Exp Ther 273: 101-112.

See RE (2005). Neural substrates of cocaine-cue associations that trigger relapse. Eur J Pharmacol 526: 140-146.

See RE (2009). Dopamine D1 receptor antagonism in the prelimbic cortex blocks the reinstatement of heroin-seeking in an animal model of relapse. Int J Neuropsychopharmacol 12: 431-436.

Selye H (1936). A syndrome produced by diverse nocuous agents. Nature 138: 32-36.

Shaham Y, Funk D, Erb S, Brown TJ, Walker CD, Stewart J (1997). Corticotropin-releasing factor, but not corticosterone, is involved in stress-induced relapse to heroin-seeking in rats. J Neurosci 17: 2605-2614.

Shaham Y, Shalev U, Lu L, De Wit H, Stewart J (2003). The reinstatement model of drug relapse: history, methodology and major findings. Psychopharmacology 168: 3-20.

Shalev U, Grimm JW, Shaham Y (2002). Neurobiology of relapse to heroin and cocaine seeking: a review. Pharmacol Rev 54: 1-42.

Shepard JD, Bossert JM, Liu SY, Shaham Y (2004). The anxiogenic drug yohimbine reinstates methamphetamine seeking in a rat model of drug relapse. Biol Psychiatry 55: 1082-1089.

Singewald N, Salchner P, Sharp T (2003). Induction of c-Fos expression in specific areas of the fear circuitry in rat forebrain by anxiogenic drugs. Biol Psychiatry 53: 275-283.

Skender ML, Goodrick GK, Del Junco DJ, Reeves RS, Darnell L, Gotto AM et al (1996). Comparison of 2-year weight loss trends in behavioral treatments of obesity: diet, exercise, and combination interventions. J Am Diet Assoc 96: 342-346.

Skinner BF (1938). The Behavior of Organisms. Appleton-CenturyCrofts: New York.

Sullivan RM, Gratton A (1998). Relationships between stressinduced increases in medial prefrontal cortical dopamine and plasma corticosterone levels in rats: role of cerebral laterality. Neuroscience 83: 81-91.

Sullivan RM, Gratton A (1999). Lateralized effects of medial prefrontal cortex lesions on neuroendocrine and autonomic stress responses in rats. J Neurosci 19: 2834-2840.

Sun W, Rebec GV (2005). The role of prefrontal cortex D1-like and D2-like receptors in cocaine-seeking behavior in rats. Psychopharmacology 177: 315-323.

Tanda G, Bassareo V, Di Chiara G (1996). Mianserin markedly and selectively increases extracellular dopamine in the prefrontal cortex as compared to the nucleus accumbens of the rat. Psychopharmacology 123: 127-130.

Thierry AM, Tassin JP, Blanc G, Glowinski J (1976). Selective activation of mesocortical DA system by stress. Nature 263: 242-244.

Torres SJ, Nowson CA (2007). Relationship between stress, eating behavior, and obesity. Nutrition 23: 887-894.

Wise RA, Hoffman DC (1992). Localization of drug reward mechanisms by intracranial injections. Synapse 10: 247-263.

Young ST, Porrino LJ, Iadarola MJ (1991). Cocaine induces striatal c-fos-immunoreactive proteins via dopaminergic D1 receptors. Proc Natl Acad Sci USA 88: 1291-1295. 